\title{
ORAL NUTRITIONAL SUPPLEMENTS AND TASTE ADHERENCE IN MALNOURISHED ELDERLY ADULT'S OUTPATIENTS
}

\author{
D.A. de Luis, O. Izaola, A Castro, J.J. Lopez, B. Torres, E. Gomez Hoyos, A. Ortola
}

\begin{abstract}
The aim of our study was to evaluate a hypercaloric sweet milkbased oral nutrition supplement in a prospective 3 daystudy designed to assess the taste preferences of this oral nutritional supplement (ONS) in elderly malnourished out-patients and the influence on adherence in daily intake during two months.A total of 28 out-patients with recent weight loss were included in this study. One flavour (chocolate, vanilla or strawberry) was administered each day in a random way during three consecutive days. In the first three days, patients were asked to fulfill two questionnaires in order to reflect ONS tolerance and acceptance. Sweet and aftertaste were better for chocolate flavour than for vanilla or strawberry flavours. Patients who chose vainilla took a total of $96.3+7.4$ average bricks during outpatient followup ( $1.60+0.3$ per day), patients who chose chocolate took $76.8+15.0$ bricks $(1.28+0.8$ per day) and patients who chose strawberry bricks taken $60.3+19.5$ bricks $(1.10+0.7$ per day), with a significant difference with vainilla flavour $(\mathrm{p}<0.01)$. The improvement of weight (vanilla $+1.0+0.8 \mathrm{~kg}$ vs chocolate $+0.5+0.8 \mathrm{~kg}$ vs $0.6+1.0 \mathrm{~kg}: \mathrm{p}=0.03$ ), tricipital skinfols (vanilla $+1.5+0.3 \mathrm{~mm}$ vs chocolate $+1.1+0.4 \mathrm{~mm}$ vs $0.7+0.3 \mathrm{~mm}: \mathrm{p}=0.03$ ), prealbumin levels (vanilla $+4.2+0.8 \mathrm{mg} / \mathrm{dl}$ vs chocolate $+3.9+0.7 \mathrm{mg} / \mathrm{dl}$ vs $+3.6+1.0 \mathrm{mg} / \mathrm{dl}: \mathrm{p}=0.01)$ and transferrin levels (vanilla $+100.0+21.8 \mathrm{mg} / \mathrm{dl}$ vs chocolate $+75.5+18.8$ $\mathrm{mg} / \mathrm{dl}$ vs $63.8+14.1 \mathrm{mg} / \mathrm{dl}: \mathrm{p}=0.03$ ) was higher in patients treated with vanilla ONS than chocolate or strawberry ONS. The three flavoured ONS taste preferences are similar although the consumption is high in vanilla flavoured ONS.
\end{abstract}

Key words: Oral nutrition supplements, outpatients, tolerance, acceptance, flavour.

\section{Introduction}

Undernutrition is a multifactorial disorder caused by reduced nutritional intake, metabolic effects of underlying disease and other factors such as therapeutic interventions, diagnostic interventions, age, educational levels, and socioeconomic status of the patient (1). Although in some cases improvement of the quality or quantity of food supplied can ameliorate the problem, in many cases the person concerned is simply unable or unwilling to consume sufficient normal food to meet their requirements to manage the disease-related malnutrition (DRM). The prevalence of protein energy undernutrition for residents of long term care facilities is between $23 \%$ and $85 \%$, and up to $65 \%$ of residents have unintended weight loss and undernutrition (2). For example, in our area the prevalence is around $23 \%$ in hospitalyzed

Center of Investigation of Endocrinology and Nutrition, Medicine School and Dept Endocrinology and nutrition Hospital Clinico Universitario. University of Valladolid. Valladolid Spain.

Corresponding Author: Dr. D. A de Luis, Professor Associated of Clinical Nutrition, Head of Institute of Endocrinology and Nutrition. Medicine Schooll. Valladolid University. C/Los perales 16. (Urb Las Aceñas)Simancas 47130 Valladolid Spain tfno. 3498342000 fax34983331566 email dadluis@yahoo.es patients with the Mininutritional assessment test (3).

Oral nutritional supplements (ONS) have been accepted as an integral part of the medical treatment of DRM in both hospital and the community. Several benefits have been found for ONS use, including reduced length of stance (4), inpatient episode cost (5), complication rates (6), depressive symptoms (7), readmission rates (8) and improved lean body mass recovery (9). However, the data highlights challenges in compliance in both the hospital and community settings $(10,11)$. ONS preference and compliance is affected by a multiple factor such as composition, product availability, cost, site of administration (hospital vs community) and personal preferences such as taste. It has been reported that taste fatigue may occur when ONS are consumed regularly over a prolonged period (12), probably in relation with a low level of appetite but also because patients do not like the flavour, texture and/or smell of such ONS.

The aim of our study was to evaluate a hypercaloric sweet milkbased oral nutrition supplement in a prospective 2 month-study designed to assess the taste preferences of this ONS in malnourished elderly outpatients and the influence on adherence in daily intake in a community setting. 


\section{Material and methods}

The study was approved by the Research and Ethics Committee at the Hospital Clinic Universitary of Valladolid, prior to recruiting the study participants. All participants provided informed consent. Table 1 summarize the composition of the used ONS. A set of three flavours of a hypercaloric oral nutritional supplement (ONS) (Fresubin Energy ${ }^{\circledR}$ ) was selected to performed the study.

A total of 28 out patients (age $>65$ years) with recent weight loss ( $>5 \%$ during previous 3 months or $>10 \%$ during previous 6 months or less than $70 \%$ of calorie requirements estimated intake for a period greater than 7-10 days) were enrolled in this study, all patients received two bricks per day of this ONS during two months. Exclusion criteria included; ongoing infections, major gastrointestinal disease, cancerous disease with active treatment, severely impaired hepatic function (total bilirrubin concentration $>3.5 \mathrm{mg} / \mathrm{dl}$ ) and/or renal function (serum creatinine concentration $>3 \mathrm{mg} / \mathrm{dl}$ ), dysphagia, steroids treatment, medication that could modulate weight and alcohol habit during the study period. With the objective that the patient chose one flavour, they were administered for three consecutive days a brick of each flavour (chocolate, vanilla or strawberry) in a random way. From the fourth day, the patients received the favorite flavour for 2 months. After the fourth day, number of ONS taking during 2 months were recorded. A dietitian checked daily intake of ONS. The study finally included 28 patients requiring oral nutritional support (cardiac patients, $\mathrm{n}=12$; geriatrics patients, $\mathrm{n}=8$; digestive disease, $\mathrm{n}=4$; neurological patients, $\mathrm{n}=4$ ).

\section{Procedures}

In all patients a complete history, nutritional examination, biochemical parameters and taste preferences were performed at baseline and after 2 months' intervention. Nutritional assesment included measurements of body weight, height, body mass index $(\mathrm{kg} / \mathrm{m} 2)$ and the circumferences and tricep skinfold of the midarm. Assessment body weight was measured to an accuracy of $0.1 \mathrm{Kg}$ and body mass index computed as body weight/ (height2). A caliper (Omron, LA, CA) was used to measure tricipital skinfold and a measuring tape was used to determine midarm circumference. Biochemical evaluation included glucose, creatinine, sodium, potassium, albumin, prealbumin and transferrin serum levels. Fasting blood samples were drawn for measurement of glucose $(70-110 \mathrm{mg} / \mathrm{dl})$, creatinine (0.6$1.1 \mathrm{mg} / \mathrm{dl})$, sodium (135-145 meq/L), potassium (3.5$5 \mathrm{meql} / \mathrm{L})$, albumin $(3,5-4,5 \mathrm{gr} / \mathrm{dl})$, prealbumin $(18-28$ $\mathrm{mg} / \mathrm{dl}$ ) and transferrin (250-350 mg/dl) (Hitachi, ATM, Manheim, Ger).

\section{Taste Preferences}

Fresubin Energy ${ }^{\circledR}$, a commercially available nutritional sip feed, was choosen for this study as it was identified to be the most often prescribed in our Health Area. Patients were asked to consume the three different flavours of this ONS during three consecutive days (2 ONS per day, according to the nutritional prescription). At fourth day patients chose the favorite flavour and recorded the consumption of this flavour during 2 months. Before starting the evaluation, participants were seated in a quiet room, and asked to score the product. The evaluation was explained to patients individually. The sensory evaluation was performed by scoring two questionnaires in the first three days for reflecting ONS tolerance and acceptance. After evaluating each product, subjects were also asked to rank each favour. These both questionnaires were based on 10-point visual analogue scale wich related on parameteres such as aftertaste, savour, taste, preference for flavours, impact on digestive tolerance and appetite (table 2). It has been previously shown that VAS was a reliable pool to assess taste preference (13).

\section{Statistical analysis}

A power calculation based on taste preference was performed. Twenty-five patients were necessary to detect an improvement of 2 point in any question of visual analogue scale, with an error type $\mathrm{I}<0.05$ and a statistical power of $80 \%$. Authors thinks that an improvement of 2 point will be considered as a relevant changed because it represents a $20 \%$ of total points of the scale. The results were expressed as average \pm standard deviation. The distribution of variables was analyzed with KolmogorovSmirnov test. ONS ratings and nutritional parameters were compared using one-way analyses of variance (ANOVA) followed by Scheffe's post-hoc test, or Student's test, when appropriated. The statistical package used was (SPSS 15.0, IL, USA).

\section{Results}

The mean age was $71.7+4.3$ years and sex distribution was (12 females and 16 males). The average body mass index was $(21.1+/-3.4 \mathrm{~kg} / \mathrm{m} 2)$ and weight $(56.3+/-$ $10.8 \mathrm{~kg}$ ), Levels of biochemical markers were; glucose $(100.7+/-10.7 \mathrm{mg} / \mathrm{dl})$, creatinine $(0.8+/-0.3 \mathrm{mg} / \mathrm{dl})$, sodium $(138.3+/-3.3 \mathrm{meq} / \mathrm{L})$, potassium $(4.4+/-0.9$ $\mathrm{meql} / \mathrm{L})$, albumin $(3.1+/-0.7 \mathrm{gr} / \mathrm{dl})$, prealbumin $(16.7+/-$ $6.1 \mathrm{mg} / \mathrm{dl})$ and transferrin $(170.2+/-45.1 \mathrm{mg} / \mathrm{dl})$.

All enrolled patients completed the study and tested the three flavours of ONS and answered the two questionnaires. Among significant differences in patients acceptance (table 2), on the visual analogic scale questionnaire with 1 meaning "not at all" and 10 "very much", sweet was better for chocolate flavour $(3.1+1.9$ 
points) than for vanilla flavour $(2.6+2.0$ points; $\mathrm{p}<0.03)$ and strawberry flavour $(2.6+2.1$ points; $\mathrm{p}<0.02)$ (table 3$)$. Chocolate flavour ONS were rated as have more aftertaste $(3.0+2.0$ points $)$ than vanilla $(2.5+2.1$ points; $<<0.01)$ and strawberry $(2.1+1.5$ points; $p<0.04)$ (table 3$)$. There was no significant difference in other parameters or the total summatory of the three flavours (table 3). There was no significant difference on tolerance among ONS flavours (table 3).

Table 1

Composition of oral nutritional supplement (Fresubin Energy $\left.{ }^{\circledR}\right)$

\begin{tabular}{ll}
\hline & (1 unit 200 ml) \\
\hline Total energy(Kcal) & 300 \\
Protein (g) & $11.2(15 \%)$ \\
Total lipid (g) & $11.6(35 \%)$ \\
Saturated lipids $(\mathrm{g})$ & 0.8 \\
Monounsaturated lipids $(\mathrm{g})$ & 7.6 \\
Polyunsaturated lipids(g) & 2.2 \\
Carbohydrate (g) & $37.6(50 \%)$ \\
Dietary fiber $(\mathrm{g})$ & 0.5 \\
\hline
\end{tabular}

Table 2

The 10 Point visual analogic scale questionnaire used in the study

\section{A. Acceptance}

Did you like this drink? Not at all (0)- very much (10)

Did you find it sweet? Not at all (0)- very much (10)

Did you find it salty? Not at all (0)- very much (10)

Did you find it bitter? Not at all (0)- very much (10)

Did you find it acid? Not at all (0)- very much (10)

Did it have an aftertaste? Not at all (0)- very much (10)

Did you have nauseas after you drank it? Not at all (0)- very much (10)

Were you hungry for the following meal after you drank it? Not at all (0)- very much (10)

How did you feel after drank it? Very badly (0) very well (10)

\section{B. Tolerance}

How did you feel today $i$ Very badly (0) - very well (10)

Did you have nauseas? Not at all (0) - very constantly (10)

Did you have vomiting? Not at all (0) - very constantly (10)

Did you have acidity reflux in the mouth? Not at all (0) - very constantly (10)

Did you have bellyache? Not at all (0) - very constantly (10)

Did you feel inflated belly? Not at all (0) - very constantly (10)

Did you have stomach pain? Not at all (0) - very constantly (10)

Did you have flatulence? Not at all (0) - very constantly (10)

How many stools did you have today? Number

Which was their consistency? Very liquid. Very hard

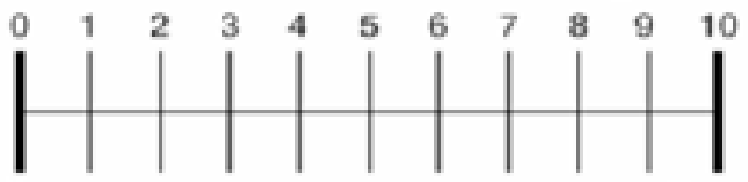

After completing the questionnaires with the three flavors, 35.7\% ( $\mathrm{n}=10)$ patients preferred vanilla, 32.1\% ( $=9$ ) chocolate and $32.1 \%$ ( $n=9$ ) strawberry (no statistical differences). No differences were detected in average age (vanilla $68.7+10.3$ years vs chocolate $65.7+9.2$ years vs strawberry $64.0+14.3$ years) or sex distribution ( $40 \%$ females vs $44.4 \%$ females vs $44.4 \%$ females). Patients who chose vainilla took a total of $96.3+7.4$ average bricks during outpatient followup $(1.60+0.3$ per day), patients who chose chocolate took $76.8+15.0$ bricks $(1.28+0.8$ per day) and finally patients who chose strawberry bricks taken $60.3+19.5$ bricks $(1.10+0.7$ per day), with a significant difference with flavored vainilla $(\mathrm{p}<0.01)$.

\section{Table 3}

Acceptance and tolerance assessing with the 10 point visual analogic scale questionnaire at basal time

\begin{tabular}{|c|c|c|c|}
\hline Flavour & Vanille & Chocolate & Strawberry \\
\hline Did you like this drink? & $6.2+2.1$ & $5.8+2.1$ & $6.2+2.2$ \\
\hline Did you find it sweet? & $2.6+2.0$ & $3.1+1.9^{*}$ & $2.6+2.1$ \\
\hline Did you find it salty? & $0.01+0.2$ & $0.02+0.1$ & $0.0+0.0$ \\
\hline Did you find it bitter? & $0.01+0.3$ & $0.1+0.4$ & $0.0+0.0$ \\
\hline Did you find it acid? & $0.0+0.0$ & $0.0+0.0$ & $0.08+0.1$ \\
\hline Did it have an aftertaste? & $2.5+2.1$ & $3.0+2.0^{*}$ & $2.1+1.5$ \\
\hline $\begin{array}{l}\text { Did you have nauseas after } \\
\text { you drank it? }\end{array}$ & $0.5+1.0$ & $0.3+0.7$ & $0.4+1.0$ \\
\hline $\begin{array}{l}\text { Were you hungry for the } \\
\text { following meal after you drank } \\
\text { it? }\end{array}$ & $4.6+2.4$ & $4.9+2.1$ & $5.0+2.0$ \\
\hline $\begin{array}{l}\text { How did you feel after drank } \\
\text { it? }\end{array}$ & $6.1+1.3$ & $6.1+1.3$ & $5.7+1.9$ \\
\hline Summatory & $22.4+5.7$ & $23.1+4.3$ & $21.9+6.5$ \\
\hline How did you feel today $i$ & $5.4+1.4$ & $5.8+1.3$ & $5.3+1.4$ \\
\hline Did you have nauseas? & $0.4+0.7$ & $0.1+0.4$ & $0.1+0.2$ \\
\hline Did you have vomiting? & $0.0+0.0$ & $0.0+0.0$ & $0.0+0.0$ \\
\hline $\begin{array}{l}\text { Did you have acidity reflux in } \\
\text { the mouth? }\end{array}$ & $0.04+0.2$ & $0.0+0.0$ & $0.0+0.0$ \\
\hline Did you have bellyache? & $0.33+0.6$ & $0.30+1.0$ & $0.34+1.2$ \\
\hline Did you feel inflated belly? & $0.7+1.1$ & $0.8+1.3$ & $0.7+1.2$ \\
\hline Did you have stomach pain? & $0.4+0.9$ & $0.7+1.7$ & $0.4+1.4$ \\
\hline Did you have flatulence? & $0.9+2.0$ & $1.1+2.2$ & $0.6+2.1$ \\
\hline $\begin{array}{l}\text { How many stools did you have } \\
\text { today? }\end{array}$ & $1.0+0.6$ & $1.0+0.5$ & $1.0+0.7$ \\
\hline Which was their consistency? & $0.4+0.9$ & $0.5+1.1$ & $0.7+1.1$ \\
\hline
\end{tabular}

${ }^{*} \mathrm{p}<0.05$ with other flavours

There are not statistical differences among basal biochemical and epidemiological data of these three flavour groups of patients (table 4). After the intervention with ONS, a statistical increase of weight, body mass index, tricipital skinfold, midarm circumference, albumin, prealbumin and transferrin was observed in the three groups (table 4 ). The increase of weight (vanilla $+1.0+0.8$ 
Table 4

Biochemical and anthropometric parameters, basal and after 2 months of intervention

\begin{tabular}{|c|c|c|c|c|c|c|}
\hline \multirow[t]{2}{*}{ Parameter } & \multicolumn{2}{|c|}{ Vanilla } & \multicolumn{2}{|c|}{ Chocolate } & \multicolumn{2}{|c|}{ Strawberry } \\
\hline & Basal & 2 months & Basal & 2 months & Basal & 2 months \\
\hline Weight (kg) & $56.2+4.5$ & $57.2+3.6^{*}, \$$ & $55.8+4.7$ & $56.3+4.0^{*}$ & $54.5+3.6$ & $55.0+4.1^{*}$ \\
\hline $\mathrm{BMI}\left(\mathrm{kg} / \mathrm{m}^{2}\right)$ & $21.2+2.9$ & $21.3+2.4$ & $21.0+1.6$ & $21.1+1.5$ & $20.9+1.9$ & $21.0+1.6$ \\
\hline TS (mm) & $9.2+3.5$ & $10.7+2.6^{*}, \$$ & $7.8+3.1$ & $8.9+3.3^{*}$ & $9.6+3.0$ & $10.3+3.0^{*}$ \\
\hline $\mathrm{MC}(\mathrm{cm})$ & $21.3+4.5$ & $21.6+3.1^{*}$ & $21.4+3.7$ & $21.8+3.1^{*}$ & $20.9+3.0$ & $21.3+3.7^{*}$ \\
\hline Glucose (mg/dl) & $99.0+8.0$ & $99.9+7.2$ & $100.1+6.2$ & $101.1+9.1$ & $101.1+5.3$ & $99.1+7.8$ \\
\hline Creatinine (mg/dl) & $0.6+2.1$ & $0.4+1.6$ & $0.8+0.2$ & $0.7+1.2$ & $0.9+1.0$ & $1.0+1.0$ \\
\hline Sodium (meq/1) & $137.4+8.9$ & $136.6+8.7$ & $139.3+4.2$ & $140.3+6.8$ & $140.1+6.2$ & $139.9+6.2$ \\
\hline Potassium (meq/L) & $4.7+1.9$ & $4.5+1.1$ & $4.9+1.2$ & $4.3+1.9$ & $4.6+1.3$ & $4.9+1.1$ \\
\hline Albumin (g/dl) & $3.5+0.9$ & $4.1+1.1^{*}$ & $3.1+1.1$ & $3.7+1.4^{*}$ & $3.0+1.0$ & $3.5+1.2^{*}$ \\
\hline Prealbumin (mg/dl) & $16.9+5.0$ & $21.1+4.4^{*} \$$ & $15.8+2.3$ & $19.7+2.9^{*}$ & $18.8+4.3$ & $22.4+2.8^{*}$ \\
\hline Transferrin (mg/dl) & $170.9+9.6$ & $278.1+9.7^{*} \$$ & $175.5+9.8$ & $240.5+7.8^{*}$ & $165.5+24.8$ & $228.8+9.8^{*}$ \\
\hline
\end{tabular}

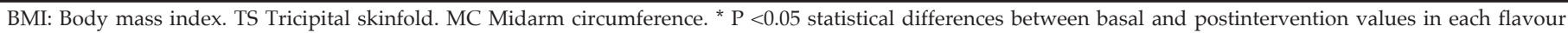
group. $\$ \mathrm{P}<0.05$ statistical differences among delta values in different flavour groups.

$\mathrm{kg}$ vs chocolate $+0.5+0.8 \mathrm{~kg}$ vs $0.6+1.0 \mathrm{~kg}: \mathrm{p}=0.03)$, tricipital skinfols (vanilla $+1.5+0.3 \mathrm{~mm}$ vs chocolate $+1.1+0.4 \mathrm{~mm}$ vs $0.7+0.3 \mathrm{~mm}: \mathrm{p}=0.03$ ), prealbumin (vanilla $+4.2+0.8 \mathrm{mg} / \mathrm{dl}$ vs chocolate $+3.9+0.7 \mathrm{mg} / \mathrm{dl}$ vs $+3.6+1.0$ $\mathrm{mg} / \mathrm{dl}: \mathrm{p}=0.01)$ and transferrin (vanilla $+100.0+21.8 \mathrm{mg} /$ dl vs chocolate $+75.5+18.8 \mathrm{mg} / \mathrm{dl}$ vs $63.8+14.1 \mathrm{mg} /$ $\mathrm{dl}: \mathrm{p}=0.03)$ was higher in patients treated with vanilla ONS than chocolate or strawberry ONS.

\section{Discussion}

The main result of our work is the best adherence to the high-calorie vanilla-flavored ONS in malnourished outpatients with supplementation criteria. A better improvement with in anthropometric and biochemical parameteres were reported with vanilla flavour than other flavours, too. The chocolate flavour was rated as sweeter than the vanilla and strawberry flavours. However, these results in both questionnaires have not effect on ambulatory compliance of ONS.

Adherence to ONS is widely discussed in the medical literature. A systematic review carried out in the year 2012 (14) that brought together part of the evidence published to date, has shown that adherence to the ONS is regular. The authors reported a significantly higher percentage in studies carried out in the community than in the hospital setting. In clinical practice, the ONS are useful to supplement feeding in patients with nutritional deficit (15). They cannot be used as sole source of nutrition during long term (16), because they are complete in one or more nutrients but they are incomplete in their vitamin and mineral composition. This low compliance of ONS could be explain by low palatability, monotony effects, and taste changes of patients. In this outpatient context, repeated intake of the same ONS over time may contribute to monotony and the abandoning of ONS. It seems also crucial to ensure that patients are offered flavours that they like; however, there was no clear preference for one of the three flavours, although the chocolate flavour was superior in sweetness. Despite the lack of differences in the initial questionnaires, the filling was superior with the vanilla flavour.

Previous studies focused on taste preferences for ONS have been shown that patients prefer the taste of milkbased versus fruit juice based ONS (18-20). In one study (20), fruit-juice typed ONS, which are often considered to be more easily accepted by the patients, obtained mediocre scores and unflavoured ONS was never chosen more than 5 days. Our present study showed that chocolate flavour seemed to be slightly more appreciated in sweetnees score than vanilla or strawberry-flavoured ones, as reported in a previous short-term study with inpatients (21). Moreover, Darmon et al (20) showed that chocolate-flavour products seemed to be slightly less appreciated than vanilla or strawberry. In other publications, sweetness appears to be one of many factors contributing to the palatability of ONS (22). However, McGough et al (23) showed that oncological patients rated elemental ONS (with a typical bitter taste) as favourably as polymeric ONS and significantly better than peptide ONS. Some studies in children have shown different results. For example, Cohen et al (24) showed that a fresh milk-based supplements were the preferred type of oral nutrition supplement in paediatric oncology patients. One study (25) have detected significant agerelated differeces in both sweetness detection and recognition thresholds.

In addition, the number of bricks that patients tooks at home was also higher with vanilla flavour. The consumption of a food is linked to sensoy experience. Those experiences that are deemed pleasurable are most 
likely to be pursued. In our present study, the high total amount of extra calories in patients with vanilla ONS made a more significant increase on weight, tricipital skinfold, prealbumin and trasferrin than chocolate- and strawberry flavoured products. Perhaps vanilla must be the flavour indicated in all these outpatients, regardless of the outcome of the initial questionnaires. We suppose that taste fatigue occurs faster following prolonged consumption of chocolate and strawberry ONS than vanilla. Our results corroborate other work (23) indicating that an initial good palatability rating does not predict successful long-term compliance with a nutritional supplement.

Our study has limitations: first, it was only a shortterm evaluation of two months; second, the population was heterogeneous including patients of different age, sex and diseases. Some variables need to be controlled, such smoking behaviour, different disease states and drugs, that are known to influence taste perception. We controlled, a lot of factors as exclusión criteria, but a lot of uncontrolled variables could modulate taste. Third, patients evaluated each product only once. Thus, it is not known wheter the study would produce the same results if the participants repeted the sensory evaluation of the same products at a later date. Four, the patient is unblinded in this interventional study. Finally, the patients could modulate their preferences, for example Williams et al (26) showed that many patients (23\%) would sacrifice taste for the benefits of renal ONS.

In conclusion, our study shows that ONS are an acceptable mode of nutritional support in outpatients with an improvement of weight and serum proteins. The three flavoured ONS taste preferences are similar although chocolated flavoured ONS has high sweetness score than vanilla and strawberry flavours. The consumption is high in vanilla flavoured ONS during external follow-up. A better improvement in anthropometric and biochemical parameteres were reported with vanilla flavour than other flavours. Further studies are needed with different ONS and during a long-term period, to detect factors that influence on maintance of ONS consumption.

Conflict of interest: The authors declare that they have no conflict of interests.

Ethical standards: All procedures performed in studies involving human participants were in accordance with the ethical standards of the institutional and / or national research committee and with the 1964 Helsinki declaration and its later amendments or comparable ethical standards.

Informed consent: Informed consent was obtained from all individual participants included in the study.

\section{References}

1. Naber TH, Schermer T, de Bree A, et al. Prevalence of malnutrition in nonsurgical hospitalized patients and its association with disease complication. Am J Clin Nutr 1997; 66:1232-9
2. Ljungqvist O, van Gossum A, Sanz M, de Man F. The European fight against malnutrition. Clin Nutr 2010;29:149e150

3. de Luis DA, Lopez Guzman A. Nutritional status of adult patients admitted to internal medicine departments in public hospitals in Castilla y leon, Spain A multi-center study. Eur J Intern Med 2006;556-560.

4. Somanchi M, Tao X, Mullin GE. The facilitated early enteral and dietary management effectiveness trial in hospitalized patients with malnutrition. JPEN J Parenter Enteral Nutr. 2011;35(2):209-216

5. Lawson RM, Doshi MK, Barton JR, Cobden I. The effect of unselected postoperative nutritional supplementation on nutritional status and clinical outcome of orthopaedic patients. Clin Nutr. 2003;22(1):39-46.

6. Beattie AH, Prach AT, Baxter JP, Pennington CR. A randomised controlled trial evaluating the use of enteral nutritional supplements postoperatively in malnourished surgical patients. Gut. 2000;46(6):813-818

7. Gariballa S, Forster S. Effects of dietary supplements on depressive symptoms in older patients: a randomised double-blind placebo-controlled trial. Clin Nutr. 2007;26(5):545-551

8. Norman K, Kirchner H, Freudenreich M, Ockenga J, Lochs H, Pirlich M. Three month intervention with protein and energy rich supplements improve muscle function and quality of life in malnourished patients with nonneoplastic gastrointestinal disease a randomized controlled trial. Clin Nutr. 2008;27(1):48-56.

9. Jensen MB, Hessov I. Dietary supplementation at home improves the regain of lean body mass after surgery. Nutrition.1997;13(5):422-430.

10. McMurdo ME, Price RJ, Shields $M$, et al. Should oral nutritional supplementation be given to undernourished older people upon hospital discharge? A controlled trial. J. Am Geriatr Soc 2009; 57: 2239-45

11. Lawson RM, Doshi MK, Ingoe LE, et al. Compliance of orthopaedic patients with postoperative oral nutritional supplementation. Clin Nutr. 2000; 19: 17175

12. Nieuwenhuizen WF, Hugo W, Ridgy P, Hetherington MM. Older adults and patients in need of nutritional support: review of current treatment options and factors influencing nutritional intake. Clin Nutr 2010; 29: 160-69

13. Rahemtulla Z, Baldwin C, Spiro A, et al. The palatability of milk-based and non-milk-based nutritional supplements in gastrointestinal cancer and the effect of chemotherapy. Clin Nutr 2005;24:1029e37

14. Hubbart G, Marinos E, Holdoway A, Stratton R. A systematic review of compliance to oral nutrition supplements. Clin Nutr 2012;31:293-312

15. Stratton RJ, ELia M. Are oral nutritional supplements of benefit to patients in the community? Findings from a systematic review. Curr Opin Clin Nutr Metab Care 2000; 3: 311-315.

16. Valero Zanuy MA, León Sanz M. Evidence-based use of oral nutritional supplements. Endocrinol Nutr 2005; 52: 34-40.

17. Ravasco P. Aspects of taste and compliance in patients with cancer. Eur J Oncol Nurs 2005;9(Suppl. 2):S84e91

18. Bolton J, Shannon L, Smith V. Comparison of short-term and long-term palatability of six commercially available oral supplements. J Hum Nutr Diet 1990;3:317e21.

19. Poustie VJ, Watling RM, Ashby D, Smyth RL. Taste preference for oral calorie supplements in children with cystic fibrosis, healthy children and healthy adults. J Hum Nutr Diet 1999; 12:301e6.

20. Darmon P, Karsegard V, Nardo P, Dupertuis Y, Pichard C. Oral nutritional supplements and taste preferences: 545 days of clinical testing in malnourished in-patients. Clinical Nutrition 2008; 27: 660-665

21. de Luis DA, Izaola O, Lopez JJ, Torres B, Gomez Hoyos E. Oral Nutritional Supplements and Taste Adherence in Malnourished Adults Inpatients, Effect on Adhesion during Hospital Stance.Ann Nutr Metab. 2015;67(4):205-9.

22. Kennedy O, Law C, Methven L, Mottram D, Gosney M. Investigating agerelated changes in taste and affects on sensory perceptions of oral nutritional supplements. Age Ageing. $2010 ; 39(6): 733-8$.

23. McGough C, Peacock N, Hackett C. Taste preferences for oral nutrition upplements in patients before and after pelvic radiotherapy: a double-blind controlled study. Clin Nutr 2006;25:906e12.

24. Cohen J, Rosen K, Russell KK, Wakefield CE, Goodenough B. Paediatric oncology patient preference for oral nutritional supplements in a clinical setting. Support Care Cancer. 2011 Sep;19(9):1289-96.

25. Kennedy O, Law C, Methven L. Investigation age-related changes in taste and affects on sensory perceptions of oral nutritional supplements. Age and Ageing 2010;39:733-738.

26. Williams RF, Summers AM. Do hemodialysis patients prefer renal-specific or standard oral nutritional supplements? J Ren Nutr. 2009;19:183-8 